Int. J. Curr. Res. Med. Sci. (2017). 3(5): 105-110

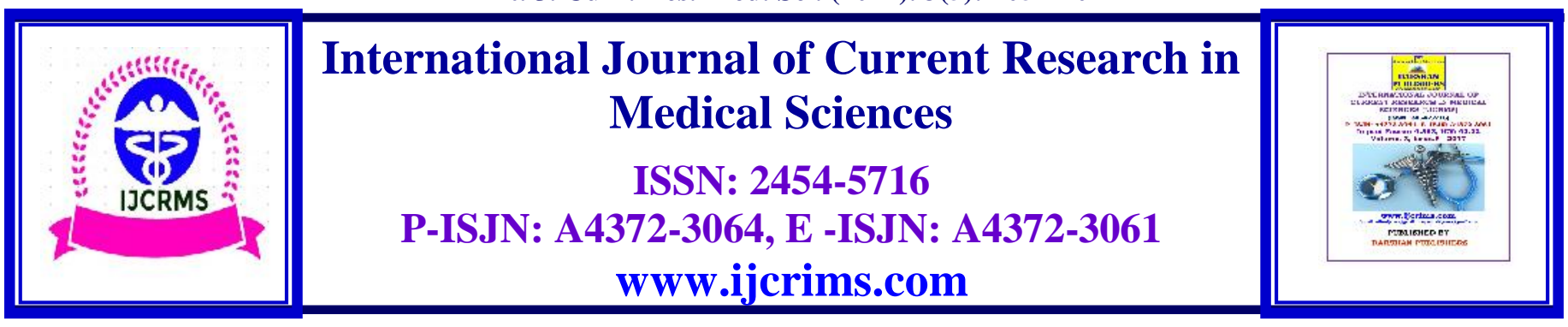

\title{
Role of gene Xpert MTB/ RIF assay in diagnosis of Tubercular Pleural Effusion
}

\author{
*Amarendra Kumar Shukla, **Nirmal Chand Kajal, **Balbir \\ Malhotra,***Sandeep Gupta, *Nishanth P.S., *Ashi Singh, ****N.S. Neki \\ *Junior Resident, **Professor, ***Assistant Professor, Department of Chest and TB, \\ Govt. Medical College, Amritsar, Punjab, India, 143001 \\ *****Professor Medicine, Govt. Medical College, Amritsar, India, 143001 \\ Corresponding Author: Dr.Amarendra Kumar, Junior Resident, Dept. of Chest and TB, \\ Govt. Medical College, Amritsar, Punjab, India, 143001 \\ E-mail: shuklaamarendrakumar@gmail.com
}

\begin{abstract}
Background: Approximately $15 \%$ to $20 \%$ of tuberculosis (TB) cases in India are estimated to have extrapulmonary tuberculosis, and tuberculous effusion being the second most common extrapulmonary manifestation after tuberculous lymphadenitis.

Due to its paucibacillary nature, it is difficult to demonstrate tubercle bacilli by the standard staining procedures which is the gold standard for diagnosis, thus leading to a large number of cases being undiagnosed or misdiagnosed. Now, it has further been complicated by the emergence of multidrug resistance. In December 2010, World Health Organization endorsed the Gene Xpert MTB/RIF technology for diagnosis of mycobacterium tuberculosis and rifampicin resistance which is providing result within 2 hour.

Aims: This study was done with an aim to know the role of Gene Xpert in the diagnosis of tubercular pleural effusion.

Results: A total of 136 patients of pleural effusion with strong clinico-radiological and pathological suspicion of tubercular etiology were included in our study and their pleural fluid was examined for Gene Xpert MTB/RIF. In 20.58\%(28) patients, Mycobacterium tuberculosis was detected and out of these, 21\%(6) had rifampicin resistance.

Conclusion: Because of its rapidity, simplicity, and sensitivity, Gene Xpert MTB/RIF technology is emerging as a novel and promising technique to diagnose tuberculous effusion and rifampicin resistance, which was undiagnosed most of the time. Although, it has limited availability at present, and for this more research studies should be conducted.
\end{abstract}

Keywords: Gene Xpert MTB/RIF Assay, Tuberculous effusion, Multidrug resistance 


\section{Introduction}

India is the highest tuberculosis burden country with World Health Organization (WHO) statistics for 2013 giving an estimated incidence of 2.1 million cases of tuberculosis for India out of a global incidence of 9 million cases ${ }^{1}$. India accounts for one fourth of the global TB burden. In 2015, an estimated 28 lakh cases occurred in india and 4.8 lakh people died due to $\mathrm{TB}^{2}$. India has the highest burden of both TB and MDR TB based on estimates reported in Global TB report $2016^{3}$.

In India, total $17 \%$ cases of extrapulmonary tuberculosis were reported in $2016^{4}$. Tuberculous pleural effusion has been reported as the most common form of extra pulmonary tuberculosis in certain areas of India but worldwide pleural TB is the second commonest manifestation of extra pulmonary $\mathrm{TB}^{5}$. The clinical presentation of extrapulmonary tuberculosis is atypical and due to paucibacillary nature of extrapulmonary specimen and lack of diagnostic means, they often remain either undiagnosed or misdiagnosed.

In December 2010 WHO endorsed the Gene Xpert MTB/RIF technology and released a recommendation and guidance for countries to incorporate the new test into their programmes ${ }^{6}$.

In 2013, the World Health Organization (WHO) endorsed the use of Gene Xpert MTB/RIF assay for extrapulmonary tuberculosis ${ }^{7}$.

Gene Xpert MTB/RIF is cartridge-based nucleic acid amplification test having fully integrated and automated amplification and detection using real time polymerase chain reaction(PCR),providing result within 2 hours. It is a highly specific test as it uses 3 specific primers and 5 unique molecular probes to target RpoB gene of mycobacterium tuberculosis (MTB). No cross-reactions have been observed with other bacterial species tested, thereby excluding non-tubercular mycobacteria(NTM) ${ }^{8}$.

This study was undertaken to evaluate the possible utility of Xpert MTB / RIF as an option for an accurate and timely diagnosis of Pleural TB and detection of rifampicin resistance in a tertiary health care setting at Govt. Medical College, Amritsar.

\section{Materials and Methods}

This is an observational prospective study done in the Department of Chest and Tuberculosis, Government medical college, Amritsar. This study was conducted after approval from the institution's ethical committee and taking informed consent of the patients .The study included 136 clinico-radiologically and pathologically suspected patients of tubercular pleural effusion, coming to outpatient department or admitted in chest and TB hospital, Amritsar.

\section{Inclusion criteria:-}

1. Patients having clinical feature of tubercular pleural effusion.

2. Pleural effusion on chest $\mathrm{X}$ - ray and ultrasonography.

3. Exudative pleural effusion by Light's criteria, lymphocytic predominant and ADA more than 40unit/litre .

4. Patients age more than 12 year of age.

5. Patients giving consent for the study.

\section{Exclusion criteria:-}

1. Transudative pleural effusion.

2. Patients with well documented chronic history of heart failure, nephrotic syndrome, liver cirrhosis .

3. Cases with empyema thoracic.

4. Contraindications to thoracocentesis like patient on mechanical ventilation, uncooperative patients, bleeding diathesis, patient on anticoagulation therapy.

5. Patients on antitubercular treatment.

6. Patients age less than 12 year of age.

7. Patients not giving consent for the study.

All specimens were collected by thoracocentasis and fluid was examined for cytology, biochemistry, adenosine deaminase test and Gene Xpert MTB/RIF assay. The fluid was centrifuged at $3000 \mathrm{rpm}$ for 15 minutes. The supernatant was discarded and the sediment was processed for Gene Xpert MTB / RIF test. Lysing 
agent was added to the sediment in a ratio of $2: 1$ and kept for 15 minutes. During this period, the sample was shook vigorously twice. Later on, $2 \mathrm{ml}$ sediment was transferred to Gene Xpert cartridge and cartridge was placed in Gene Xpert instrument and results were obtained within 2 hours.

\section{Results}

136 cases of strongly suspected pleural effusion were included in the study. Fluid was exudative in nature by Light's criteria, lymphocytic predominant, and ADA more than 40unitslitre. In the study, males were 82 and females were 54
(Table 1). Clinical features with which the patient presented are described in Table 2.

Pleural fluid ADA and lymphocyte counts are described in Table 3 and 4. Chest radiology represented right sided pleural effusion in $79 \%$, left sided plerural effusion in $18 \%$ and bilateral effusion in 3\% cases (Table 5). Gene Xpert detected MTB in $20.58 \%$ cases and Rifampacin resistance in $21 \%$ cases (Table 6).

Correlation of MTB detected patients by Gene Xpert with ADA value and lymphocyte count were described in graph 1 and 2 .

\section{Table 1: Study Patients (Gender):}

\begin{tabular}{|l|c|c|}
\hline Total & Male & Female \\
\hline 136 & $82(60 \%)$ & $54(40 \%)$ \\
\hline
\end{tabular}

Table 2: Clinical features:

\begin{tabular}{|l|c|c|}
\hline Clinical feature & Present & percentages \\
\hline Fever & 125 & $92 \%$ \\
\hline Chest pain & 97 & $72 \%$ \\
\hline Cough & 92 & $68 \%$ \\
\hline Dyspnea & 70 & $52 \%$ \\
\hline
\end{tabular}

Table 3: Pleural Fluid ADA:

\begin{tabular}{|l|c|c|c|}
\hline \multirow{2}{*}{ ADA unit/litre } & No. of cases & \multicolumn{2}{|c|}{ Gene Xpert MTB/RIF assay } \\
\cline { 3 - 4 } & & MTB detected & $\begin{array}{c}\text { Rifampicin } \\
\text { resistance }\end{array}$ \\
\hline $40-59$ & 26 & 2 & 0 \\
\hline $60-79$ & 49 & 8 & 2 \\
\hline$>80$ & 61 & 18 & 4 \\
\hline
\end{tabular}

Table 4: Lymphocyte Count:-

\begin{tabular}{|c|c|c|c|}
\hline Lymphocyte count & \multirow{2}{*}{ Cases } & \multicolumn{2}{|c|}{ Gene Xpert MTB/RIF assay } \\
\cline { 2 - 3 } & & MTB detected & $\begin{array}{c}\text { Rifampicin } \\
\text { resistance }\end{array}$ \\
\hline $60-69 \%$ & 8 & 1 & 0 \\
\hline $70-79 \%$ & 13 & 3 & 0 \\
\hline $80-89 \%$ & 42 & 9 & 2 \\
\hline $90-100 \%$ & 73 & 15 & 4 \\
\hline
\end{tabular}


Int. J. Curr. Res. Med. Sci. (2017). 3(5): 105-110

Table 5: Chest Radiology (CXR):

\begin{tabular}{|c|c|c|}
\hline Right side effusion & Left side effusion & Bilateral effusion \\
\hline $68 \%$ & $28 \%$ & $4 \%$ \\
\hline
\end{tabular}

Table 6: Gene Xpert MTB / RIF:

\begin{tabular}{|l|c|c|c|}
\hline Gene Xpert assay & TOTAL & MALE & FEMALE \\
\hline MTB Detected & 28 & 20 & 8 \\
\hline Rifampicin resistance & 6 & 5 & 1 \\
\hline
\end{tabular}

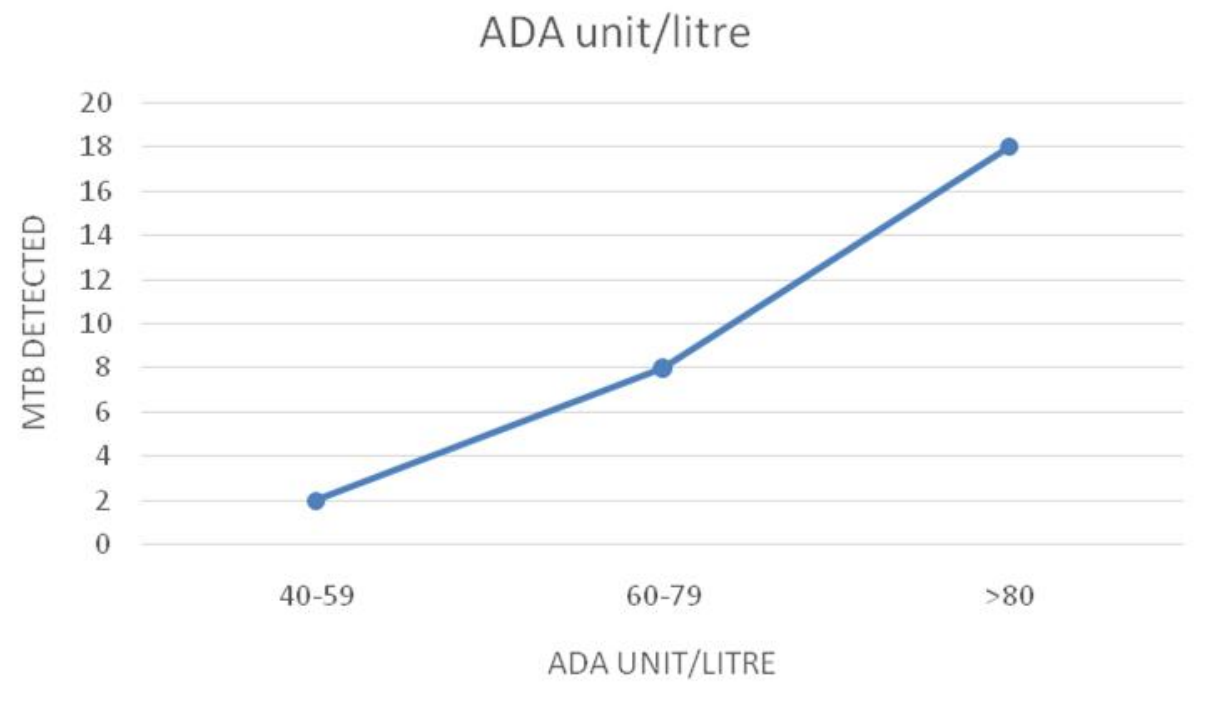

Graph 1: Correlation between MTB detected by Gene Xpert patients and ADA value

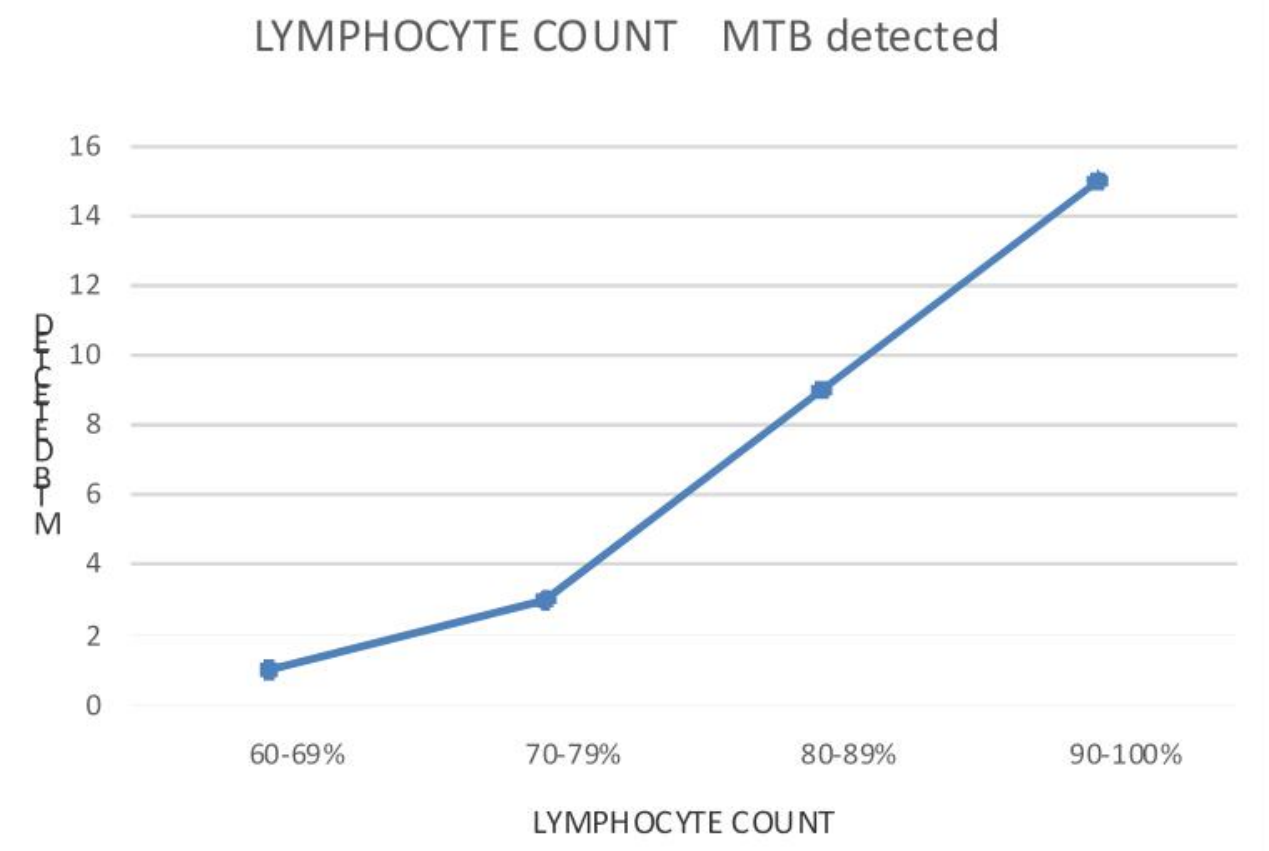

Graph 2: correlation between MTB detected by Gene Xpert patients and lymphocyte count 


\section{Discussion}

Demonstration of tubercular bacilli as well as caseating granuloma are the gold standard for the diagnosis of tuberculosis ${ }^{9-10}$. Inspite of all the efforts most of the time it is negative in case of tubercular pleural effusion due to its paucibacillary nature and etiology of pleural fluid remain undiagnosed or misdiagnosed .Pleural fluid analysis by cytology, biochemistry and ADA is not always diagnostic, similar picture may be present in some other diseases thus, creating diagnostic confusion.

Our study was planned to know the role of Gene Xpert MTB/RIF in the diagnosis of tubercular pleural effusion and rifampicin resistance as not many studies are available in the literature. The results showed MTB detection in $28(20.58 \%)$ cases, out of which males were $20(14 \%)$ and females were $8(6 \%)$. Out of 28 MTB detected patients , 6(21\%) patients had rifampicin resistance (5 male and 1 female).

There was a significant positive correlation between MTB detected patients by Gene Xpert and ADA value $(r=0.92, p<0.05)$, and similarly significant positive correlation was also seen with MTB detected patients and lymphocyte count $(\mathrm{r}=0.97, \mathrm{p}<0.05)$.

Ahmed et al in 2014 did a similar study with a total of 19 pleural fluid samples in which Gene Xpert MTB/RIF was positive in $3(15.8 \%)^{11}$.

Similarly, Gene Xpert results with a study by Javed $\mathrm{N}$ et al was $8 \%$ positivity for MTB detection $^{12}$.

Other international studies like Friedrich SOI et $\mathrm{al}^{13}$,Chris-topher DJ et $\mathrm{al}^{14}$ and John $\mathrm{K}$ et $\mathrm{al}^{15}$ showed sensitivity and specificity on pleural fluid as $25 \%$ and $100 \%, 16 \%$ and $100 \%, \& 28.7 \%$ and $96.6 \%$ respectively.

Analysing the above studies result shows sensitivity between $8 \%$ to $28.7 \%$.

\section{Conclusion}

The results of present study show that Gene Xpert MTB/RIF assay could come to play a significant role in routine tubercular pleural effusion diagnosis and detection of drug resistance tuberculosis, where resources of pleural fluid culture are limited, case burden is high and is time consuming, whereas results of Gene Xpert MTB/RIF are available in same day with acceptable sensitivity.

\section{Source of funding: Nil}

Conflict of interest: None declared

\section{References}

1. Global Tuberculosis Control 2014, WHO, Geneva, 2014 www . who.int/tb/publications/globalreport/.

2. http://www.tbcinda.gov.in March 2017, chapter 2 TB Disease burden in India.

3. http://www.tbcinda.gov.in March 2017,chapter 2 TB Disease burden in India.

4. http://www.tbcinda.gov.in March 2017, chapter 15,Table:1,TB case notification in 2016.

5. Sharma SK, Mohan A. Extra Pulmonary Tuberculosis, Indian J Med Res 2004; 120: $316-53$.

6. TB CARE I. International Standards for Tuberculosis Care, 3rd edition. 2014. Available at URL: www.istcweb.org. Accessed on March, 2014.

7. World Health Organization (Country Office for India). Standards for TB Care in India. Available at URL: http://www.tbcindia.ic.in / pdfs /stci\%20 Book.

8. Boehme CC. "Rapid molecular detection of tuberculosis and rifampin resistance" N Engl J Med 363, 2010, 1005-1015. final\%20\%20060514.pdf. Accessed on 17 June, 2014.

9. Light RW. Update on tuberculous pleural effusion. Res-pirology, 2010; 15: 451 - 8 . 
10. Koegelenberg CF, Bolliger CT, Theron J etal. Direct comparison of the diagnostic yield of ultrasound assi-sted Abram and Tru - cut needle biopsies for pleural tuberculosis. Thorax, 2010; 65: 857 - 62 .

11. Ahmad N S, Sana khan, Aneeqa Shamshad Butt. Rapid detection of Mycobacterium tuberculosis and Rifampicin Resistance in extra pulmonary samples using Gene Xpert MTB/RIF assay. IOSR Journal of Dental and Medical Sciences 11/2014; 13(11):2279- 861. DOI: 10.9790/0853-131145053.

12. Javed N, Aslam M, Mushtaq AM, Khan J, Sheen ZM et al; Role of Gene Xpert in the diagnosis of tuberculous pleural effusion comparison with pleural biopsy ERJ Sept. 2014.

13. Friedrich SO 1, Von Groote - Bidlingmaier F, Diacon AH. Xpert MTB/RIF Assay for diagnosis of pleural tuberculosis. $\mathrm{J}$ Clin Microbiol. 2011: 4341-42.

14. Christopher DJ, Shumacher SG, Michal JS. Perfor-mance of Xpert MTB / RIF on pleural tissue for the dia-gnosis of pleural tuberculosis. Eur Respir J. 2013; 42 (5): 1427 $-29$.

15. John K, Lusiba, Lydia Nakiyingi, Brue J, Kirengaetal July 22, 2014. Doi: 10, 137/Journal. Pone. 0102702.

\begin{tabular}{|c|l|}
\hline \multicolumn{2}{|c|}{ Access this Article in Online } \\
\hline Q & Website: \\
\hline & www.ijcrims.com \\
& Subject: \\
Quick Response Code & \\
\hline
\end{tabular}

How to cite this article:

Amarendra Kumar Shukla, Nirmal Chand Kajal, Balbir Malhotra, Sandeep Gupta, Nishanth P.S., Ashi Singh, N.S. Neki. (2017). Role of gene Xpert MTB/ RIF assay in diagnosis of Tubercular Pleural Effusion. Int. J. Curr. Res. Med. Sci. 3(5): 105-110.

DOI: http://dx.doi.org/10.22192/ijcrms.2017.03.05.015 